\title{
Sexuality, Love and Eroticism: Methodology of Distinguishing*
}

\author{
Philipp Tagirov \\ Department of Social Philosophy \\ Peoples' Friendship University of Russia (RUDN University) \\ 6 Miklukho-Maklaya Street \\ Moscow, Russian Federation 117198 \\ E-mail: tagirov_fv@rudn.university
}

\begin{abstract}
The following article proposes the approach of distinguishing of three core components of the complex phenomenon of eros which are love, sexuality and eroticism. The proposed approach can be the foundation for further studies of the social ontology, psychology and phenomenology of love and sexuality in general as well as for the investigations of gender identity, processes of social transformation named "sexual revolution" and so on. The author emphasizes the key elements of love (the exclusiveness of its object and the deep personal care for the being of the other), sexuality (pleasure of the physiological nature and desire of this pleasure) and eroticism (principal unproductivity and transgression) that distinctly reveal their essential specifics.
\end{abstract}

Keywords-desire; eros; identity; love; methodology; personality; pleasure; sexuality; subject; transgression

\section{INTRODUCTION}

The symbolic predisposition of the subject of our conversation to the dynamic and diverse interpretations is obvious to us at a lexical level. In English, the word "love" is very polysemantic, multivalued, and, as a consequence, plastic. With different love, but using the same word (and, therefore, with somewhat similar attitude), we love our pets, our Motherland/Fatherland, our folks, those who gave birth to us, our work, we love sports, we love to drink and love Picasso. We use the same word depicting how we feel about our beloved ones, but sometimes we "love" them at sunset and at dawn with different meanings, manifesting and realizing ourselves in different interpretations of the same word. What is even more remarkable - as we know, we do not find a strict analogue to the word "love", for example, in ancient Greek. Instead of one polysemantic concept, they used several ones, but with a more clearly defined area of interpretation. Or, in other words, the ancient Greeks had to use several different concepts in order to describe what we mean by the single concept of "love." You can, of course, argue, recalling the various synonymous units from the English (like, adore, experience passion, etc.), but in this language we usually find words synonymous with the word "love", which differ in intensity of feelings, whereas the

*The publication has been prepared with the support of the RUDN University Program 5-100.
Greek concepts diverge not only in this intensity, but also in their direction. Or this very intensity itself (as well as a certain internal structure of the feeling) varies depending on whom this feeling is addressed to, and the direction itself can be considered as primary for the demarcation of concepts.

\section{USAGE OF GREEK CONCEPTS FOR "LOVE": ADDRESS Is KNOWN}

As we know, the main lexical units, one way or another accordant to the English word "love", in the ancient Greek language are "eros", "philia", "storge" and "agape". Sometimes in the research literature we come across various attempts to expand this series with a help of other concepts, for example, xenia - hospitality that is prescribed friendly attitude even to a complete stranger who has become your guest.

Eros is an ascending love, rising upwards, and the object of eros, whether it is physical or spiritual, is put in a higher place in comparison with the one who is captured by the power of eros. Thus, the erastes (the loving one) seek after the eromenos (the beloved one) as an object of desire, which is more beautiful than himself, although his own social position, the status is more often and higher than the one of his beloved one. The classical explanation of the erotic aspiration can be found in Plato's "Symposium" [1]: eros is a desire to possess the beauty, which one lacks (which implies that a person strives for such a good that he would have a greater good than now). In the case of spiritual eros, we also assume the ascent of the individual self to a higher step towards the object of his love.

Philia is a concept that, by its polysemantic character, probably resembles English word "love" to the greatest extent. Philia means affection, sympathy for a variety of things and actions. Concerning relations between people, first of all, philia appears as the love of equals, or, in other words, friendship love, love of the free and love that is free itself, and finally, love associated with virtue. Such it was prescribed to be by Aristotle. We can only speculate on how widespread such a love was in real life and how it corresponded to the Aristotelian prescriptions, but the fact that it occupied a highly important place in the ancient discourse about love is obvious. 
The next type of love, storge, is more modestly presented in this discourse than eros, philia or agape. In contrast to the xenia mentioned above (directed toward a stranger, a person who is not the part of a family or even of a community), storge, on the contrary, is generally addressed inward of the family space. This gentle, kind feeling, which we have towards our relatives, is indifferent to their age or place in the family hierarchy. In this vein, the storge can be defined as a love meaning tenderness (rather than passion) towards one's close being.

Finally, in the same family space, we usually find the fourth of the main types of love - agape. In its direction, agape is essentially opposite to the ascending eros, this is a descending love, the love of the higher to the lower. However, it should have nothing in common with arrogance and contempt, which so often accompany our descending glance, this is love, coupled with care and sacrifice. In the family it is primarily the love of parents for their children. With this same love, as the Christians will reveal later, God loves people, loves like the father loves his children. And one Christian must address another one with agape, for although they are equal as brothers and sisters in Christ, but their love for each other is also sacrificial and descending, for this is not just human love, but love that God loves one person through another, which is, first of all, a vessel for descending divine love.

\section{Distinguishing Love, SEXUALITY AND EROTICISM}

So, we can assume that in the case of English (and, for example, of Russian) language we mostly have a synonymic series, the units of which differ more quantitatively, qualitatively referring to a single field, though very diffuse on its borders. While in Ancient Greek we meet concepts that differ qualitatively from one another, depending on their orientation and their addressing different objects and even fields. We could further assume the greater universality (and democracy?) of the contemporary concept of "love" in English and the higher organization and orderliness (which, in principle, is generally typical for the relations in traditional society) of the whole field of "love" as it was represented in discourse of the Ancient Greeks. But what is more important to us is that in different discourses not only the interpretation of the subject of our present analysis will differ, but the very method (or principle) of how these interpretations are organized and how they are integrated into the broader cultural context. And, consequently, it will be different how the subject "tries on" himself or herself the meanings connected with the concept of love and related concepts, and also in what way he or she inscribes his or her identity, project of the self and the steps leading to its realization, in these meanings. But in spite of the fact that we do not always find similar constellations of these meanings in different historical cultures, in each of these cultures the basic dispositions were relatively clearly delineated, and in the case of several coexisting discourses, we see the determined priority of these discourses when considering a specific subject or a specific situation. However, in a contemporary post-traditional society, we find a slightly different situation where the fractionality, eclecticism and inconsistency of the discursive material complicates the emphasis - or even a discussion on the possible disposition of accents - not only in a general multi-discursive space, but often in particular discourses.

Today the lack of a common conceptual understanding of the matter we study gives rise to confusion of the problematic fields of eros, love and sexuality. Of course, these three elements very often come together and in agreement, but even in this situation, which seems to be close to the ideal, each of them retains its specificity, its essence, bringing it into two other adjacent elements and modifying them. Without distinguishing eros from sexuality, sexuality from love, love from eros, the individual inevitably experiences difficulties at the very level of self-identification in the question, whether he or she acts as a subject of eros, love or sexuality. By asserting one's own subjectiveness in one or another "practice of the self" (as M. Foucault defined it [2]), with such inconsistency, we risk mixing practices of eroticism, sexual practices and practice of personal love, taking one after another and not revealing their holistic harmonious unity or failing to achieve a full realization of ourselves in one of these three domains because of the divergence of performing practices and the postulated identity.

How could we trace the main core lines, not only inherent in eros, love and sexuality, but also defining their specificity and thus allowing us to distinguish one from another and confirm the presence or absence of a given element in a particular discourse or in this or that practice?

In love, we first of all distinguish its personal disposition meaning that love is personal, addressed to a particular being in all its uniqueness. Love, as it is, for example, formulated by N. Berdyaev is always a "love of the face" [3], in contrast to "lechery" or "philandering" where there is only "love of love" and the personality of another human being is secondary. Importance of a person, of this very "he" or "she", opens for us the second feature of love: its exclusiveness. Love excludes the beloved from all, he or she is no longer reducible to anyone or to anything else, even if we do not succeed in formulating the rational explanation for this exclusivity. This is irrationality, illogicality of love, for it knows only singularities, always only singularities that do not add up, multiply, or fit into proportions, and therefore, any laws and theorems can be accepted only conditionally and nominally.

To derive common or even private rules, a certain reducibility of objects to each other is necessary. That typicality, which in its essence is antithetical to the situation of "love of the face", and therefore of personal love in general, is fundamentally representative for sexuality. After all, there are no irreplaceable objects in sexuality for us, there are only different types, some of which attract us to a greater extent while others - to a lesser one. However, although the typicality of a sexual object distinguishes sexuality from love, for which the object is always exceptional, it is not in its object we find the specificity of sexuality. 
Despite the fact that quite forthright and detailed theoretical discussion of sexuality began already about a century ago within the framework of psychoanalytic discourse [4], we still have some difficulties with the definition of sexuality. And the problem lies in our temptation to give in to one of the two extremes: to determine the subject too narrowly, leaving behind the less obvious manifestations of sexuality (against which $\mathrm{Z}$. Freud also warned), or vice versa - too widely (for which many reproached and still reproach the psychoanalytic theory of culture, morality, religion, and the unconscious itself), so that the boundaries of sexuality will be blurred, and almost everything will be potentially predisposed to be attributed to this or that manifestation of sexuality (and if everything is sexuality, then what is the point in defining the concept, which, as it turns out, has no limits?).

Postponing the problem of the borderlands of sexuality until a more appropriate moment, we could have less arguments about its core and in the first place regard pleasure (of a physiological nature) and the desire (of this pleasure) as the key points of the sexual. Pleasure and desire are closely linked and act as a pair, where the first is not only the result of the embodiment of the second, but also the reason for the revival of the second. The pleasure in which the desire seems to have found its solution, reaching its peak, slides into a pit of deafness and devastation, but after a while it floats up again - but already in our memory, as already experienced, no longer as a state experienced by us, but as an object of our recollection and wish, that is something exterior, lost and - once again desired. And in this context, let the physicality of this pleasure not obscure the possibility of the absence of a direct physiological contact between the subject and the object of sexual desire: the desired pleasure is always an imaginary pleasure, wanting real pleasure, we imagine it but we imagine it as a physical pleasure.

Since pleasure is the desired product of sexuality, we can, for example, follow G. Bataille [5] or J. Baudrillard [6] in their assertion that sexuality is productive even when it is not reproductive (what allows us to admit that reproductive sexuality is included in sexuality in general, but does not exhaust it). Eros, unlike sexuality, is specific in that it is fundamentally useless, it does not produce any good, but, on the contrary, as shown, for example, by G. Bataille, always implies waste. However, it is precisely the unproductive nature of the eros that allows Bataille put it on top of the whole utility pyramid. Anything, as Bataille notices, is valuable to us for its usefulness. And it is useful, the more it serves a higher purpose, the more it helps us to obtain something more valuable. However, this more valuable object in turn is valuable to us because of its own usefulness, that is, by helping to achieve a new goal, which again will only turn into a means to achieve greater utility. Is there a final, the highest goal, the one for which all other goals are, in this pyramid of goals? If yes, then it should be absolutely useless, bringing no product, otherwise it will be needed again for something else, not for its own sake. And such an unproductive, useless thing, according Bataille, is eros.

The main thing in understanding eros is a transgression. Movement "through", action "in spite of", existence "in opposition". Not progress, not regress, but the aspiration of a human being to transcend its limits, transcending aspiration without any hope of a successful outcome, of some useful product, of a happy ending. Any useful product would be a concrete good, though added to the individual, but finite, and therefore obscuring the totality of his being. It is this totality that is the object of the unremovable longing of a person who realizes himself as the finite one. It is the thirst for this totality that underlies all transgressive acts of man and mankind, namely it is the basis of erotic impulse, of eroticism itself. Man cannot fully fit in the logic of utility, in the logic of production. However hard we try to hide in the finite things, the longing for the totality, for the infinity does not leave us, revealing itself even in the endless pursuit of the finite goods, as shown in particular by B. Vysheslavtsev [7].

In order to love, it is enough to have an object of our love and care. The realization of the subject in sexuality requires the completion of its productive cycle - the obtaining of pleasure or giving birth to a child. But the dramatic paradox of eroticism means that eroticism itself is possible only because of its own impossibility, more precisely, the impossibility of fulfillment an erotic impulse. In the end, according to Bataille [8], eros never allows a person to get what it promises, because it promises everything. A person either retreats at some point, or the drama of a transgression finds a solution in the death of its subject. However, as we understand, this impossibility of eroticism hardly stops a person (who gives in to eroticism again and again in his or her desire for the totality), because everything possible is always not everything, but everything is always impossible.

So, eros necessarily implies a transgression. Transgression is a litmus test, a distinctive feature: eros exists only where there is a transgression. But the question of the inverse relationship is not so obvious. Do we also deal with eros wherever there is a trance-? Probably, the problem here is similar to the one we come across in the case of pansexualism. Not every pleasure associated with the functioning of the organs of our body has an obvious sexual nature (receptor pleasures from taste and smell, pleasure derived from muscular exercise during physical labor, etc.), but between the pleasures of a very different plan (especially physiological ones) it is very easy to throw bridges, they always correspond very well with each other, forming composite complexes; and this makes it possible, if desired, to find a sexual basis even in what does not seem at all sexual to us at first glance. So it is with the transgression. Not every transgression will seem to us erotic in the usual sense of the word, and it would probably be unjustifiable if we expanded the notion of eros (both physical and spiritual) so that it covers the whole field of the transgressiveness. However, since the transgression acts as a key element of eros, whenever we are dealing with a transgression, we are tempted to attribute the principle of erotisism to it.

\section{The INTEGRATION OF LOVE, SEXUALITY AND EROTICISM}

It is obvious that eros, love and sexuality can form a holistic complex in which they act as elements, creating 
more or less harmonious unity. It is also clear that people know sexuality without love, and love without sexual desire. The medieval mystic, who discovered the meaning of the transformed eros, could tell us that his eros is cleansed both from the carnal component and from personal human attachments. However, we still need to elaborate a little more on what eros, love and sexuality are for each other, how they manifest themselves in each other and what they reveal through their connection.

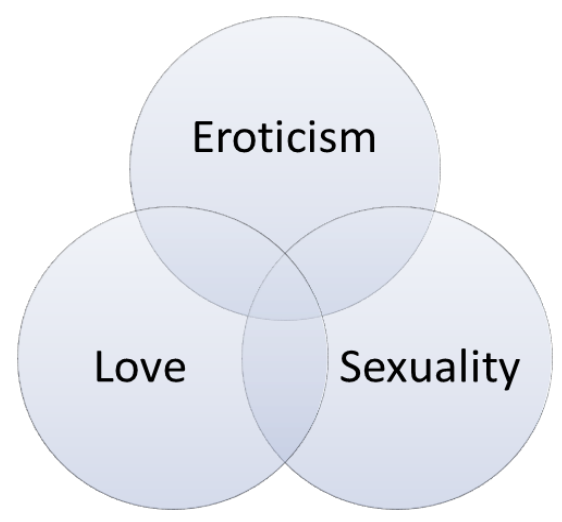

Fig. 1. The integration of love, sexuality and eroticism.

How is love represented in sexuality? First of all, it is exclusiveness of the desire (desire directed to this very person, desire inflaming by personal qualities of the individual) and exclusivity of pleasure (your partner's open eyes, in which you peer and find there this very man or woman, and no other; and it is in these eyes and this soul you want to sink endlessly). Similarly, through these key elements - desire and pleasure - eros manifests itself in sexuality. It is a question of a transgression in desire (in a case of the excessive desire when it too much exceeds the limits of the real) and a transgression in pleasure (in a situation where the boundaries of subjectivity are ecstatically eroded).

Eros in love inevitably implies the transcendence of one's own "me" for the sake of "you," self-forgetfulness and selfsacrifice. Sexuality in love brings desire for pleasure and pursuit of satisfying this desire into the field of personal care for the being of the other. The beloved here is also seen as a sexual object. The presence of love in sexuality explains the selfless desire to share pleasure with a loved one or even to sacrifice one's own pleasure for the pleasure of the other (and in this case we also find here a trace of eros).

Sexuality for eros is one of its forms, a mask, one of material incarnations of its transgressive tendency. Sexuality is not always transgressive, but when it is combined with eros, it is formed and directed by the latter, it is matter for its form, and it is a form for its essential content. Since love in eros means transgression through concentration on personal component of the other we can generally conclude that eros grants sexuality with some general direction and love forms an individual shape in this general direction, like a stream in a flow of the river.

As an example of methodological application of what was said above, we can once again return to the Greek concept that refers to "love". We can clearly see that the ancient understanding of eros definitely includes eroticism , whereas personal love and sexuality can be either present or absent in it. Speaking of philia as a love of equals, we generally don't imply transgressive eroticism, but it definitely includes a personal attitude (if it's not just a formal relationship prescribed by the society, but then it shouldn't be called "philia", it will be some kind of pseudo-philia, a simulacrum of philia) and sexuality can be either applied or not.

We also cannot find an essential presence of eroticism in storge, where there is a personal attitude and sexuality is optional. Agape is not only anti-erotic (for it is directed from the top down; in Christian version from the totality of God towards his children), but also asexual. As for xenia, with rare exceptions, we do not find in it either eroticism or sexuality (unless sexual services are prescribed by the custom of hospitality in a given culture), nor love, which, as a personal attitude, requires the revelation of the personality of the other and is impossible in relation to a stranger; and all this once again underlines our judgment that Xenia scarcely has to do with love, being exclusively external social role.

TABLE I. EROTICISM, LOVE AND SEXUALITY IN GREEK CONCEPTS OF "LOVE"

\begin{tabular}{|l|l|l|l|l|l|}
\hline & Eros & Philia & Storge & Agape & Xenia \\
\hline Eroticism & + & - & - & - & - \\
\hline Love & $+/-$ & + & + & + & - \\
\hline Sexuality & $+/-$ & $+/-$ & $+/-$ & - & - \\
\hline
\end{tabular}

Of course, by the combination of elements we cannot guess for sure what type of "love" is involved, however, we are able to conduct the reverse procedure: considering the specific type of "love" conclude what elements are inherent in it and which are not. Such a tool, taken by itself as an instrument, will hardly tell an individual which of the forms of subjectivity in eroticism, sexuality and love are right for him and which are not, but this is the necessary first step to clarifying possible "projects" and "practices of the self", without which the choice of that or another project and that or another practice will be neither meaningful nor, as a consequence, responsible.

\section{CONCLUSION}

Today, the subject of eros (understood here as a set of eroticism, love and sexuality, even if combined in various proportions) is a witness, and sometimes a participant in various theoretical pseudo-scientific and trivial discourses about the ontological status of love, its duration, its truthfulness (that there is no love or there is, but only for a short moment, there is, but only for one or two months or at best for three or four years and then it becomes a habit, etc.) discourses, that sometimes find their "confirmation" in the arguments of psychologists or biologists, sociologists and moralists. Here it is essential to ask a question: what kind of love are we talking about? About deep personal attitude? Or about sexual attractiveness? Maybe about the possibility of transgression through disposition to another person? Personal attitude or love for this exact person can hardly be 
exhausted in such a short time as, for example, one or two months, if this person was originally worthy of this love, and love was addressed to some deeply individual structures of the person and was not claimed as a fig leaf for something different. On the contrary, it is reasonable to assume that the more prolonged the term, the greater is the opportunity for the subjects for mutual revelation, mutual acceptance and interpenetration. Sex appeal, where the element of novelty, as often claimed, plays not the least role, of course, seems to be a rather capricious lady, however, is it worth calling feeling, when personal disposition to another subject is not capable of outliving impersonal sexual aspiration, love? As for eros, it makes sense to ask the question, how many people at all have the happiness (or misfortune) of knowing the transgression in more than just its latent forms?

Personal love can be fraternal, parental, etc. Revealing its interconnection with eros and sexuality, and thus limiting its original semantic field, is capable of clarifying love as an intimate feeling. By expanding the concept of the sexual, started by Freud, almost everything can be seen as an object of sexual attraction, and linking sexuality to personal love and transgressive eros could save it from dangerous erosion into pointlessness. Eros in so many of its forms goes so far both from corporeality to incorporeality and from personality into impersonality (or superpersonality), that we are tempting to apply this concept to every phenomenon of our life that contains a potential charge to a transgression - that is, again, almost to everything. Coupling with love and sexuality allows us to keep humanity or materiality in the eros, even if only as forms or conditions, which we intend to transgress.

\section{REFERENCES}

[1] Plato, Symposium.

[2] M. Foulcault, The Use of Pleasure. Volume 2 of The History of Sexuality, trans. by Robert Hurley. Vintage Books, New York, 1990. Introduction, Chapter 3 ("Morality and Practice of the Self").

[3] N. Berdyaev, The meaning of the creative act. Collier Books, New York, 1962. Chapter IX

[4] S. Freud, A General Introduction to Psychoanalysis. - Horace Liveright, Inc., 1920. Lectures 20-21.

[5] G. Bataille, Eroticism, trans. by Mary Dalwood. - Penguin, London, 2001.

[6] J. Baudrillard, Seduction. - New World Perspectives, Montreal, 1990. Part 1.

[7] B. Vysheslavtsev, The ethics of transfigured eros. Respublika, Moscow, 1994. Chapter IX.

[8] G. Bataille, The History of Eroticism in The Accursed Share Volumes II \& III, trans. by Robert Hurley. Zone Books, New York, 1991. Introduction and Part 1. 